\title{
Adult Stem Cell Therapy for Stroke: Challenges and Progress
}

\author{
Oh Young Bang, ${ }^{\mathrm{a}, \mathrm{b}}$ Eun Hee Kim, ${ }^{\mathrm{b}}$ Jae Min Cha, ${ }^{\mathrm{c}, \mathrm{d}}$ Gyeong Joon Moon ${ }^{\mathrm{b}, \mathrm{e}}$ \\ aDepartment of Neurology, Samsung Medical Center, Sungkyunkwan University School of Medicine, Seoul, Korea \\ ${ }^{b}$ Translational and Stem Cell Research Laboratory on Stroke, Samsung Medical Center, Seoul, Korea \\ 'Samsung Biomedical Research Institute, Samsung Advanced Institute of Technology, Samsung Electronics Co., Ltd., Seoul, Korea \\ ${ }^{d}$ Medical Device Research Center, Research Institute for Future Medicine, Samsung Medical Center, Seoul, Korea \\ eStem cell and Regenerative Medicine Institute, Samsung Biomedical Research Institute, Seoul, Korea
}

Stroke is one of the leading causes of death and physical disability among adults. It has been 15 years since clinical trials of stem cell therapy in patients with stroke have been conducted using adult stem cells like mesenchymal stem cells and bone marrow mononuclear cells. Results of randomized controlled trials showed that adult stem cell therapy was safe but its efficacy was modest, underscoring the need for new stem cell therapy strategies. The primary limitations of current stem cell therapies include (a) the limited source of engraftable stem cells, (b) the presence of optimal time window for stem cell therapies, (c) inherited limitation of stem cells in terms of growth, trophic support, and differentiation potential, and (d) possible transplanted cell-mediated adverse effects, such as tumor formation. Here, we discuss recent advances that overcome these hurdles in adult stem cell therapy for stroke.

Keywords Stroke; Biomaterials; Stem cells; Mesenchymal stem cells

\author{
Correspondence: Oh Young Bang \\ Department of Neurology, Samsung \\ Medical Center, Sungkyunkwan \\ University, 81 Irwon-ro, Gangnam-gu, \\ Seoul 06351, Korea \\ Tel: +82-2-3410-3599 \\ Fax: +82-2-3410-0052 \\ E-mail: ohyoung.bang@samsung.com \\ Received: September 1, 2016 \\ Revised: September 15, 2016 \\ Accepted: September 18, 2016 \\ This study was supported by the Korea \\ Health Technology RED Project, the \\ Ministry of Health \&t Welfare \\ (HI14C16240000).
}

The authors have no financial conflicts of interest.

\section{Introduction}

Stroke is the leading cause of physical disability among adults. One-fourth to a half of stroke survivors are left with significant disabilities. Stem cell therapy is considered a potential regenerative strategy for patients with neurologic deficits. This review presents the most recent advances in adult stem cell therapy for stroke, focusing on improvements in its safety and efficacy profile.

\section{Search strategy and selection criteria}

We identified references for this review by searching PubMed and ClinicalTrials.gov published in English up to December 2015, with the search terms stroke, cerebral infarction, stem cells, and mesenchymal stem cells (MSCs). Additionally, we searched refer- ences from relevant articles and reviews. The final reference list was generated on the basis of originality and relevance to this topic. Because of space limitation, we are not able to discuss many potential regenerative strategies of adult stem cells therapies in depth with critical analysis. Genetically modified stem cells are mentioned only briefly because they have some limitations in the clinical use in stroke patients.

\section{Mechanisms of action of adult stem cells in stroke}

A critical limitation of adult stem cell therapy for stroke is the lack of complete understanding of mechanism of action mediating the observed therapeutic benefits. Embryonic stem cells (ESCs) and induced pluripotent stem cells (iPSCs) can replace the 
missing brain cells in the infarcted area. However, there are hurdles associated with true neuronal substitution using cell replacement to restore neuronal function after stroke, ${ }^{1}$ and ESC/ iPSC therapy was associated with tumor formation. Moreover, preclinical studies showed that most transplanted cells disappeared within a few weeks. ${ }^{2}$ In fact, a low graft persistence of transplanted cells could be a positive readout for the safety of stem cell therapies (i.e., unregulated stem cell proliferation).

Therefore, adult stem cells such as MSCs may be a good choice for stroke therapy because they secrete a variety of bioactive substances, including trophic factors and extracellular vesicles (EVs, 0.1-1 $\mu \mathrm{m}$ sized circular membrane fragments shed from the cell surface), into the injured brain, which may be associated with enhanced neurogenesis, angiogenesis, and synaptogenesis. ${ }^{3-7}$ In addition, MSCs are thought to play multiple roles, such as attenuating inflammation, ${ }^{8,9}$ reducing scar thickness, ${ }_{1}^{10}$ enhancing autophagy, ${ }_{1}^{11}$ normalizing microenvironmental/metabolic profiles, ${ }^{12}$ and possibly replacing damaged cells ${ }^{13}$ in various brain diseases.

\section{Results of clinical trials}

With current advances in understanding the effects of introducing stem cells and their mechanisms of action, several clinical trials of stem cell therapy were conducted in patients with stroke. Most clinical trials used adult stem cells, such as MSCs ${ }^{14-18}$ and bone marrow mononuclear cells. ${ }^{19-24}$ While stem cells appeared to be of some benefit in several studies, there was significant bias in subsequent studies. ${ }^{25}$

In the STARTING (STem cell Application Research and Trials In NeuroloGy) trial, autologous MSCs culture-expanded with fetal bovine serum were applied intravenously in the subacute phase of stroke..$^{15}$ Intravenous autologous MSC transplantation was safe for stroke patients through a long-term period, and may improve recovery. However, many patients in the MSC group remained significantly disabled. ${ }^{15}$ More recently, the InveST (Intravenous Autologous Bone Marrow Mononuclear Cell Therapy for Ischemic Stroke) trial tested whether intravenous infusion of autologous bone marrow mononuclear cells between 7 to 30 days after stroke onset could result in a reduction of the infarct volume and could improve neurological function at day 180 of follow-up. ${ }^{24}$ This trial failed to show effectiveness.

Because these randomized, observer-blinded trials were not pivotal efficacy trials, there can be no conclusions made regarding the efficacy of this therapy. Some of the failures in clinical trials may be predicted on the basis that there was insufficient preclinical data to support a strong clinical benefit. ${ }^{26}$ Improvement in the therapeutic efficacy of current stem cell therapies is needed before efficacy studies are conducted. Very recently, the results of a phase II, multicenter, double blind randomized controlled trial of intravenous application of allogeneic multipotent adult stem cells (the B01-02 trial of MultiStem ${ }^{\circledR}$ ) in acute stroke patients have been reported. ${ }^{18}$ MultiStem ${ }^{\circledR}$, an allogeneic "offthe-shelf" cell therapy, during acute phase of stroke (within the 24-48 hour window) was safe and significantly improved recovery and reduced mortality at one year.

\section{Hurdles of current adult stem cell therapies}

The primary hurdles for current stem cell therapies include (a) the limited source of engraftable stem cells, (b) the presence of optimal time window for stem cell therapies, (c) inherited limitation of adult stem cell potential, and (d) possible transplanted cell-mediated adverse effects, such as tumor formation or stroke (Figure 1).

First, although the optimal cell dosage and route of administration of stem cells in cardiovascular diseases are not settled, ${ }_{1}^{27}$ administration of sufficient cell dose is mandatory to have beneficial effects of stem cells. Unlike to hematogenous stem cells, the number of MSCs in bone marrow dramatically decline with age, requiring culture-expansion. ${ }^{28}$ It was reported that MSCs enter senescence and are losing their stem cell characteristics (plasticity and homing ability) during ex vivo culturing., ${ }^{4,290}$ In addition, stroke mostly occurs in elderly people, and MSCs obtained from elderly patients show the decline in proliferation, self-renewal, or differentiation capacity.

Second, the optimal time point for the application of stem cells exists, in terms of stem cell tropism toward brain and mechanistic targets of stem cells. The levels of chemokines, trophic factors, and relevant microRNAs (miRs) increased markedly in the infarcted brain during the acute phase of stroke, but decreased with time..$^{31}$ In addition, the mechanistic targets for cell therapy may differ depending on temporal windows after stroke. The application of stem cells during acute phase of stroke may be needed to have a range of paracrine and immunomodulatory effects, which lead to a reduction in secondary injury processes and stimulation of brain repair after stroke. ${ }^{32}$

Third, adult stem cells may have inherited limitations. MSCs are heterogenous and contain many different types of progenitor or stem cells, in terms of growth, trophic support, and differentiation potentials. The neurorestorative potential of MSCs may be limited in the elderly who have a limited number of neural stem/ progenitor cells (NSCs) ${ }^{33}$ and bone marrow $\mathrm{MSCs}_{1}{ }^{28}$ who are unable to receive rehabilitation therapy, ${ }_{1}^{34}$ and those with extensive damage to the subventricular region. ${ }^{15} \mathrm{An}$ attenuation of the re- 
Challenges/Hurdles

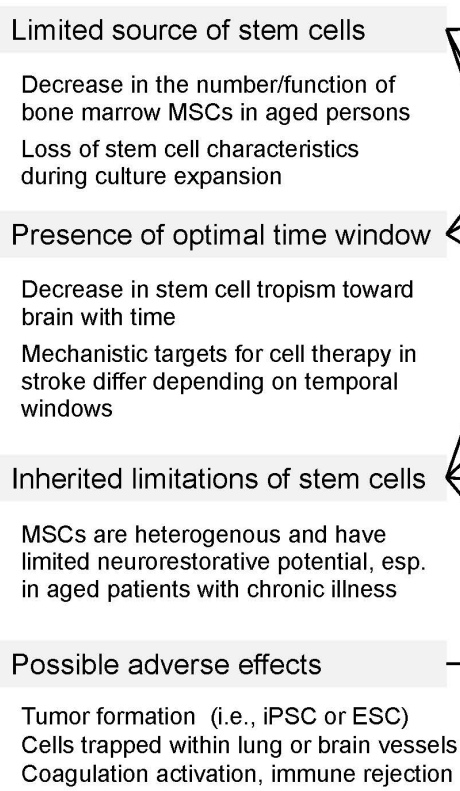

Strategies to overcome challenges

Allogeneic/different sources

- Off the self use of allogeneic stem cells

Mode of application

- Systemic approach for acute stroke

- Surgical approach for chronic fixed deficits

- BBB manipulation for $\uparrow$ MSC/trophic factors

Ex vivo manipulations

- Anoxic/ischemic preconditioning

- Isolation of functional subpopulations of MSCs

Biotechnology

- 3D bioprocessing to modify cell characteristics

- Genetic manipulation of MSCs

- Adult stem cells derived from ESCs or IPSC

Cell-free paradigm

- Stem cell-derived EVs or secretome

- Small molecules

- microRNAs or anti-microRNAs

Figure 1. Hurdles of current stem cell therapy and strategies to overcome the challenges. MSC, mesenchymal stem cell; iPSC, induced pluripotent stem cells; ESC, embryonic stem cells; BBB, blood-brain barrier; EV, extracellular vesicle.

generative potential of stem cells in aged patients with stroke could result from aging in either the donor cells (e.g., bone marrow stem cells) or the recipient cells (e.g., NSCs in the innate neurogenesis system of the brain). However, stroke-induced neurogenesis has been observed in stroke patients in their 60s and $70 s^{35}$ Although the number of NSCs decreased with age in the human brain ${ }^{33}$ and basal neurogenesis was impaired in the subgranular and subventricular zone of aged animals, the degree of neurogenesis after stroke was similar in young and old animals. ${ }^{36}$ In addition, NSCs in aged brains could be activated by application of "younger" stem cells. One recent study showed that secreted factors from the young stem cell niche rescued the numbers of NSC colonies derived from old-age subependyma, and enhanced NSC proliferation in vivo in aged animals. ${ }^{37}$ On the contrary, age-related changes could affect certain biological features of bone marrow MSCs, resulting in decreased proliferation and paracrine functions as well as increased senescence and apoptosis, which may decrease the neurogenic potential of MSCs. ${ }^{38-41}$ These findings suggest the importance of the aging/ rejuvenation of donor cells to the neurogenic potential of stem cell therapy.

In addition, the discrepancy in stem cell effects between preclinical and clinical studies may be in part derived from differences in the regenerative potential of healthy young animals and aged patients with chronic disease. One study showed that treatment with bone marrow MSCs in type I diabetic rats increased mortality and blood-brain barrier (BBB) leakage, result- ing in brain hemorrhage, and underscored the possibility that stem cell therapy may not be beneficial for diabetic subjects with stroke. ${ }^{42}$ Preclinical and clinical studies have also shown that the proliferation and angiogenic capacity of endothelial progenitor cells and MSCs were impaired in patients with coronary artery disease and metabolic disorders. ${ }^{43}$ Therefore, further studies are required examining the effects of stem cell therapies for stroke in aged animals with chronic diseases.

Lastly, a major concern with stem cell therapy is cell-mediated adverse effects, i.e., tumor formation of transplanted cells (i.e., iPSC or ESC) that may delay the recovery after stroke ${ }^{44}$ and trapping of stem cells in the lung (intravenous application) or brain vessels (intra-arterial application). ${ }^{45,46}$

\section{Recent advances in stem cell research for stroke therapy}

The following issues will be addressed in order to overcome these hurdles (Figure 1).

\section{Differential sources of stem cells}

Although bone marrow-derived MSCs are most commonly used, other sources of MSCs, such as adipose tissue or the umbilical cord, are increasingly utilized in clinical practice. This has resulted from our current understanding of the characteristics of different sources of MSCs. ${ }^{47-50}$ These other sources of MSCs outside bone marrow or allogeneic MSCs from young donors may 
address the apparent decrease in the number and function of bone marrow MSCs in aged persons. Both adipose tissue and umbilical cord are promising sources of MSCs. Adipose tissue-derived stem cells (ADSCs) are reported to have several advantages over bone marrow-derived stem cells. Relatively large number of ADSCs can be separated from subcutaneous fat tissue with minimally invasive procedures. ADSCs were reportedly superior to bone marrow MSCs in their paracrine functions ${ }^{51}$ and angiogenic potential. ${ }^{52}$ Moreover, ADSCs were more refractory to the effects of advanced donor age in a mouse model of stroke. ${ }^{47} \mathrm{MSCs}$ can also be obtained from umbilical cord blood and Wharton's jelly, etc. Umbilical cord MSCs expressed preferentially secreted factors related to neuroprotection, neurogenesis, and angiogenesis, ${ }_{1}^{49,50}$ Umbilical cord MSCs also showed favorable differentiation capabilities and low immunity. Both ADSCs and umbilical cord MSCs reportedly improved functional recovery in animal models of stroke even when administered after a delayed time. ${ }^{48,53}$

In addition, allogeneic stem cells could represent a suitable alternative to autologous stem cells. The safety of allogeneic MSC therapy may be closely related to their short-term existence in the host after the application. Allogeneic stem cells have advantages over autologous stem cells. Allogeneic MSCs are scalable from a manufacturing perspective, with standardized procedures. MSCs from younger healthy donors or iPSC- or ESC-derived adult stem cells may differ in terms of their proliferation and neurorestorative capacity, from those of cells obtained from elderly patients with chronic illness. The use of allogeneic MSCs reduces the time required to obtain a sufficient number of cells (the "off the shelf" approach). In the recent clinical trials of intravenous application of allogeneic stem cells (MultiStem ${ }^{\circledR}$ ) in patients with acute stroke, stem cells were applied within the 24-48 hours after the onset of symptoms. ${ }^{18}$ Post-hoc analysis showed that early treatment ( $\leq \mathrm{rl}$ hour) was associated with a greater benefit at one year of treatment.

However, conflicting results exist. After contact with serum, allogeneic MSCs can be injured by complement, and the viability of allogeneic MSCs after infusion is greatly reduced compared with autologous MSCs. ${ }^{54}$ Several approaches based on biomaterials or mimicry of antigen-specific peripheral tolerance have been suggested to reduce the high risk for rejection of allogeneic cells. ${ }^{55}$ Moreover, treatment of stroke with bone marrow stem cells obtained from stroke rats resulted in improved functional outcomes compared to treatment with cells from normal rats. ${ }^{56}$

\section{Mode of application of stem cells}

The mode of application of stem cells may significantly influence the number of cells delivered to target regions as well as the incidence of adverse effects. A major problem in introducing stem cells systemically is that cells may become trapped within organs that filter the blood (first-pass effect). To avoid this, strategies to minimize lung adhesion and improve the homing of systemically introduced cells are used, including different routes of administration. For example, unlike in intravenous infusions, in an intra-arterial approach, pulmonary circulation can be bypassed, which results in superior delivery and sustained presence of stem cells in the ischemic brain. ${ }^{46}$ However, an arterial approach may cause arterial occlusion, resulting in stroke; hence, this approach was not found to be superior to an intravenous approach for recovery after stroke. ${ }^{46,57}$ More recently, several studies reported that intranasal delivery of MSCs improved neurovascular regeneration and functional recovery after stroke. ${ }^{58,59}$ Intranasal delivery may provide a simple, non-invasive, and brain-specific mode for cell therapy.

Molecules larger than $400 \mathrm{Da}$ cannot pass through the BBB, which may affect the efficacy of cell therapy in stroke patients. Intravenous co-administration of stem cells and mannitol, an osmotic agent that can regulate the permeability of the BBB, may improve outcomes in stroke patients. One preclinical study showed that BBB manipulation using intravenous mannitol prior to MSC treatment resulted in increased levels of trophic factors in the infracted brain. ${ }^{60}$ As mannitol is already widely used in clinical practice, BBB manipulation using mannitol could be considered in future clinical trials. ${ }^{61}$

In terms of chemokine expression and BBB opening, chronic treatment could be advantageous with non-systemic routes (i.e., intra-arterial, intranasal, or intracerebral) and BBB manipulation. Few studies have directly compared the efficacy of various routes of delivery of MSCs, and further studies are needed.

\section{Ex vivo manipulation of stem cells and culture medium}

Decreased functional activity of stem/progenitor cells might be mediated by telomerase shortening/decreased telomerase activity, disturbances of the cell secretome, and altered interactions with the microenvironment. ${ }^{62}$ Several methods of culture expansion that improved the proliferation, survival, and trophic support, and reduced senescence of MSCs have been reported, including hypoxic/ischemic preconditioning, genetic modification of cells, trophic factor pretreatment, isolation and use of functional subpopulations of stem cells, modulation of intracellular signal cascades, and modification of the cell microenvironment.

The choice of medium is of importance for the end result of the stem cell culture. Use of human serum or human platelet lysate instead of xenogenic fetal bovine serum during MSC expansion enabled rapid expansion and rejuvenation of MSCs without adversely affecting immunophenotype. ${ }^{16,63}$ Likely, culture expan- 
sion of MSCs with serum obtained in the acute phase of stroke increased cell proliferation rates, increased trophic factor release, and decreased senescence via circulating signals from the infarcted brain area. ${ }^{64} \mathrm{~A}$ clinical trial (Clinical trial identifier NCT 01716481) will determine the effectiveness and safety of autologous MSCs that are culture expanded in autologous serum obtained as soon after stroke as possible. ${ }^{61}$ In addition, hypoxic conditions (i.e., $0.1-2 \% \mathrm{O}_{2}$, conditions similar to bone marrow) were beneficial to MSCs and might stimulate MSCs to exhibit adaptive responses. ${ }^{65-69}$

Treatment with trophic factors or chemical agents may alter MSC characteristics. Preclinical studies of various ischemic models showed that ex vivo treatment with trophic factors or chemical agents (valproate and lithium) during MSC cultivation enhanced the migration of MSCs and trophic support in the ischemic brain. ${ }^{45,70,71}$

Lastly, genetic modification of MSCs increased the trophic support of MSCs (e.g., brain-derived neurotrophic factor genemodified MSCs), and migration of MSCs to infarcted brain areas (MSCs transfected to overexpress a chemokine receptor). ${ }^{72-75}$

\section{EVs derived from stem cells}

Cell therapy using the secretome (trophic factors, cytokines, or chemokines produced through paracrine secretion) or EVs (e.g., microvesicles and exosomes) derived from stem cells could represent a new, clinically feasible, and cell-free paradigm that would avoid cell-related problems such as tumor formation and infarcts caused by vascular occlusion. Stem cells secrete EVs as well as soluble factors (e.g., trophic factors), and stroke in humans triggers the mobilization of MSC-derived $\mathrm{EVs}{ }^{76}{ }^{7} \mathrm{Es}$ harbor bioactive molecules such as lipids, proteins and miR, and EVs secreted from stem cells carry more complex cargos than other cellular sources. ${ }^{77}$ Encapsulation of bioactive molecules in EVs increases their stability and bioavailability and helps crossing the BBB. ${ }^{78,79}$ Stem cell EVs play a critical role in the exchange of information between stem cells and damaged cells and alter the behavior of the target cells (Figure 2). In recent studies, microvesicles secreted from MSCs promoted sciatic nerve regeneration in rats. ${ }^{80}$ On the contrary, astrocytes release exosomes enriched in heat shock proteins and synapsin I under stress conditions. ${ }^{81}$ Along with others, we have shown that intravenous administration of EVs derived from MSC culture media promotes functional recovery and neuro-vascular plasticity after stroke in rats. ${ }^{82,83}$ No studies have examined the effects of stem cell-derived EVs in stroke patients, but a phase 1 study of cord blood-derived MSC EVs in diabetes patients is ongoing (Clinical trial identifier NCT 02138331).

miRs are short, non-coding RNAs with a capacity to repress varied target genes. ${ }^{84}$ Caballero-Garrido et al. investigated an effect of the in vivo inhibition of miR on brain recovery after stroke and showed that intravenous anti-miR-155 injections in a mouse model of stroke improved poststroke angiogenesis and recovery. ${ }^{85}$ Extracellular miRs can be protected from degradation by RNase through encapsulation within EVs. Accumulating evidence supports that stem cell-derived EVs help to repair brain damage after stroke via miR delivery to target cells, thereby regulating the expression of genetic information and promoting a

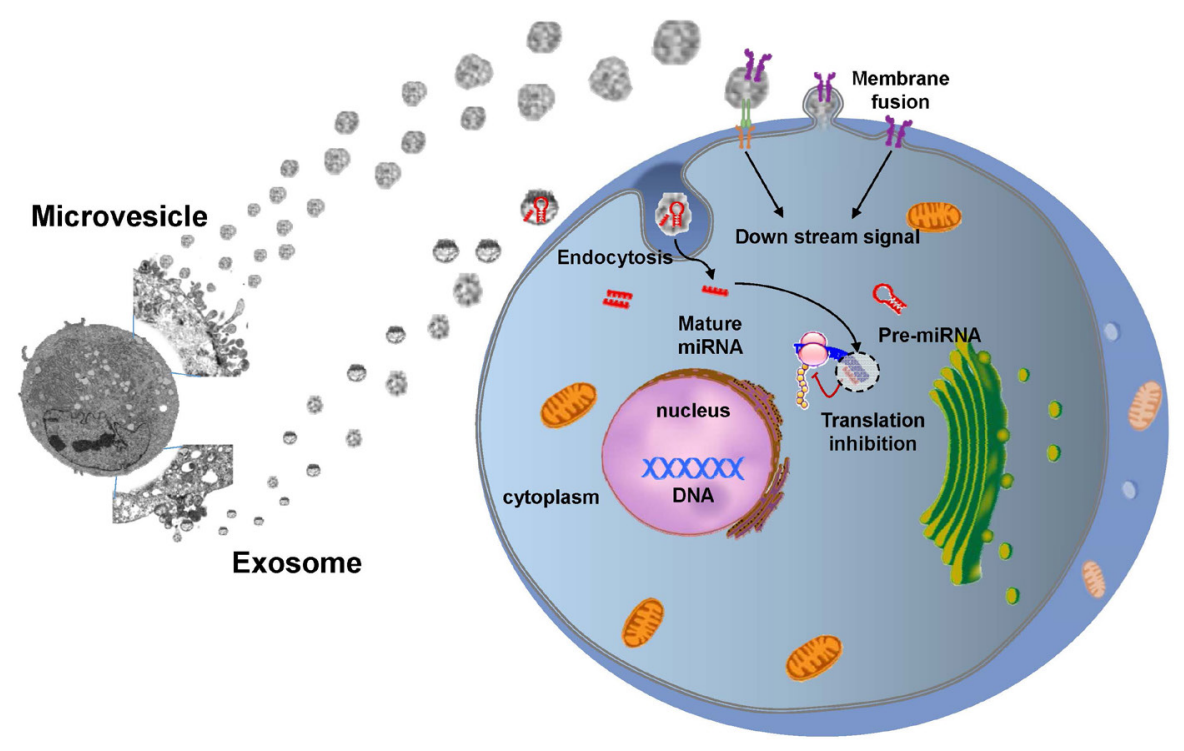

Figure 2. Exchange of information between stem cells and neural cells via EVs. Stem cell-derived EVs can transfer stem cell-specific bioactive molecules, including proteins, mRNAs, and miRs, to injured cells. Thus, EVs can trigger a regenerative program in injured cells in a paracrine manner. Conversely, injured cells may stimulate stem cells by secreting vesicles under pathological conditions. 
therapeutic response. ${ }^{86}$ For example, MSC administration increased miR-133b expression levels in rat brain after stroke and exosomal miR-133b transferred from MSCs to neurons and astrocytes regulated neurite outgrowth ${ }^{87}$ and neurovascular remodeling to promote stroke recovery. ${ }^{82}$ The efficacy of stem cells could be enhanced in principle by regulating miR expression in stem cells or EVs. miR-based therapies, including miR amplifiers and inhibitors, and artificial miRs, are currently being developed. ${ }^{88}$ Transplantation of MSCs over-expressing miR-126, promotes functional angiogenesis in the ischemic myocardium..$^{89} \mathrm{In}$ addition, modification of EV-miRs may occur during the ex vivo manipulation of stem cells, e.g., preconditioning. ${ }^{90,91}$

Lastly, administration of small molecules, biomaterials, and biologics that targets the stem cell niche is a promising field in regenerative medicine. ${ }^{92}$ Small molecules that modulate specific targets involved in the signaling and mechanisms of stem cells may be used to modulate stem cell function in vitro and in vivo. Compared to cell therapy, small molecules are relatively lower cost, more convenient to use, and offer better temporal/spatial control. ${ }^{93}$ However, relatively few studies have been conducted for stroke therapy.

\section{Application of 3D bioprocessing techniques}

To date, considerable attention has been focused on the development of novel 3D bioprocesses that can facilitate the clinical translation of stem cell research. Besides the various methods of biochemical and/or genetic preconditioning mentioned previously, the biological properties of stem cells can be manipulated by $3 \mathrm{D}$ bioprocessing techniques that physically mimic the natural microenvironments of the stem cells in vivo. ${ }^{94}$

It is becoming increasingly apparent that the native phenotype of MSCs is altered with repeated passages during culture expansion using conventional tissue culture flasks. ${ }^{95}$ With regard to this, the formation of MSC aggregates can reproduce natural $3 \mathrm{D}$ interactions between cells and the extracellular matrix or other neighboring cells, creating an "in-vivo-like" microenvironment where the phenotype and innate properties of the MSCs can be better preserved..$^{96,97}$ Current research has shown that MSCs can be easily prepared as spheroid-shaped cellular aggregates by simple 3D bioprocessing techniques, and that these 3D MSC aggregates may have advantages over MSCs from monolayer cultures for many therapeutic applications. For example, secreted anti-inflammatory, proangiogenic, and promitotic factors were highly enriched in 3D MSC aggregates. ${ }^{94,97-100}$ Furthermore, the differentiation efficiency of MSCs toward adipogenic, osteogenic, and potentially epithelial-like or neuronal-like phenotypes were also increased by these techniques. Thus, 3D culturing has been proposed as a preconditioning strategy to en- hance the therapeutic functions of the MSCs..$^{94,98,99}$

Likely, the incorporation with biomaterials can also provide stem cells with a highly biocompatible 3D-environment. Tissueengineered scaffolds with engineered biochemical/physical properties could support cellular survival in a long-term transplantation to promote integration with the host tissue. ${ }^{101}$ Theoretically, the scaffold could serve as a therapeutic cell-delivery vehicle that releases neuroprotective factors in a controlled manner, which would further promote the regeneration and functional revival of damaged neuronal tissue. ${ }^{102}$ Recently, an electrically conductive polymer scaffold was developed as a novel NSC delivery system. In this study, human NSCs were electrically preconditioned in 3D by seeding on to the scaffold, which resulted in an improved rate of recovery of neurological functions after stroke. ${ }^{103}$

In addition, culture methods to expand 3D bioprocessed stem cells should be further studied. Traditional static culture conditions limit the mass transfer of nutrients, oxygen, and metabolic wastes, resulting in a necrotic center of cellular mass while cells near the outer layer remain viable. ${ }^{104,105}$ Therefore, dynamic culture conditions are required to improve the cellular and biomolecular composition of 3D stem cell-based constructs. ${ }^{106-111}$ Bioreactor systems can offer not only well-controlled mixing of the culture media but also real-time monitoring of culture parameters. Continuous evaluation of critical culture parameters could facilitate the efficient scale-up of 3D stem cell-based constructs. ${ }^{112,113}$ To this end, reproducible, standardized 3D bioprocessing protocols could be established to customize stem cell therapy for stroke. Automated bioreactor systems would allow powerful stem cell therapies to translate to general practice, which might otherwise stay restricted to academic studies or select societal groups.

\section{Conclusions}

Clinical data are still being accumulated in patients with stroke. It remains too early to be confident that adult stem cell therapy can improve functional outcomes in patients with stroke. More evidence from randomized trials is needed. In the meantime, continuing efforts are needed at the bench, to develop stem cell strategies with enhanced therapeutic efficacy of stem cells, and at the bedside, through constant dialogues, to meet the Food and Drug Administration's regulations on stem cell use in clinical applications. The efficacy of stem cell therapy will be improved with advances in our understanding of stem cell biology and with the advances in techniques to modulate stem cell characteristics, including biotechnology and bioengineering (Figure 3). 


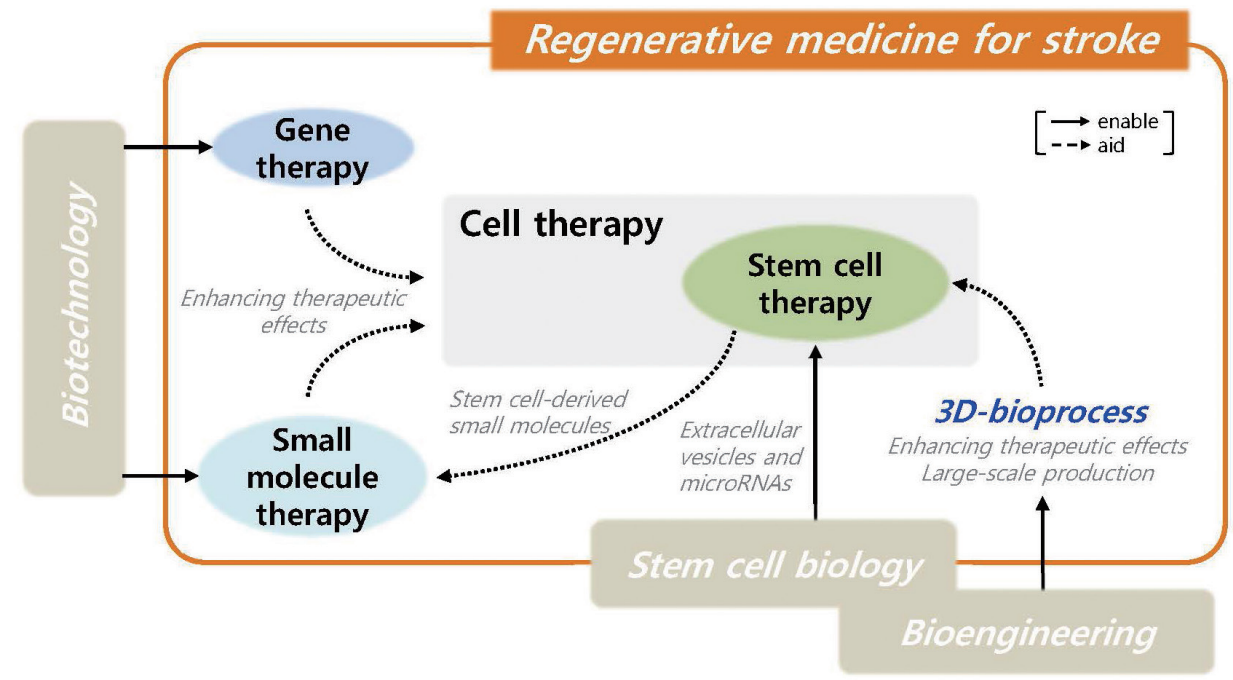

Figure 3. Advances in technologies that are required for regenerative medicine for stroke.

\section{References}

1. Dihné $M$, Hartung HP, Seitz RJ. Restoring neuronal function after stroke by cell replacement: anatomic and functional considerations. Stroke 2011;42:2342-2350.

2. Rosenblum S, Wang N, Smith TN, Pendharkar AV, Chua JY, Birk

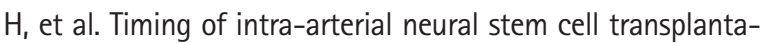
tion after hypoxia-ischemia influences cell engraftment, survival, and differentiation. Stroke 2012;43:1624-1631.

3. Chen $X$, Li Y, Wang L, Katakowski M, Zhang L, Chen J, et al. Ischemic rat brain extracts induce human marrow stromal cell growth factor production. Neuropathology 2002;22:275-279.

4. Li WY, Choi YJ, Lee PH, Huh K, Kang YM, Kim HS, et al. Mesenchymal stem cells for ischemic stroke: changes in effects after ex vivo culturing. Cell Transplant 2008;17:1045-1059.

5. Liu Z, Li Y, Zhang RL, Cui Y, Chopp M. Bone marrow stromal cells promote skilled motor recovery and enhance contralesional axonal connections after ischemic stroke in adult mice. Stroke 2011;42:740-744.

6. Song M, Mohamad O, Gu X, Wei L, Yu SP. Restoration of intracortical and thalamocortical circuits after transplantation of bone marrow mesenchymal stem cells into the ischemic brain of mice. Cell Transplant 2013;22:2001-2015.

7. Lai RC, Chen TS, Lim SK. Mesenchymal stem cell exosome: a novel stem cell-based therapy for cardiovascular disease. Regen Med 2011;6:481-492.

8. Kim YJ, Park HJ, Lee G, Bang OY, Ahn YH, Joe E, et al. Neuroprotective effects of human mesenchymal stem cells on dopaminergic neurons through anti-inflammatory action. Glia 2009;57:13-23.
9. Acosta SA, Tajiri N, Hoover J, Kaneko Y, Borlongan CV. Intravenous bone marrow stem cell grafts preferentially migrate to spleen and abrogate chronic inflammation in stroke. Stroke 2015;46:2616-2627.

10. Shen LH, Li Y, Chen J, Zacharek A, Gao O, Kapke A, et al. Therapeutic benefit of bone marrow stromal cells administered 1 month after stroke. J Cereb Blood Flow Metab 2007;27:6-13.

11. Shin JY, Park HJ, Kim HN, Oh SH, Bae JS, Ha HJ, et al. Mesenchymal stem cells enhance autophagy and increase beta-amyloid clearance in Alzheimer disease models. Autophagy 2014; 10:32-44.

12. Paik MJ, Li WY, Ahn YH, Lee PH, Choi S, Kim KR, et al. The free fatty acid metabolome in cerebral ischemia following human mesenchymal stem cell transplantation in rats. Clin Chim Acta 2009:402:25-30

13. Yamauchi T, Kuroda $Y$, Morita $T$, Shichinohe $H$, Houkin $K$, Dezawa $M$, et al. Therapeutic effects of human multilineagedifferentiating stress enduring (MUSE) cell transplantation into infarct brain of mice. PLoS ONE 2015;10:e0116009.

14. Bang OY, Lee JS, Lee PH, Lee G. Autologous mesenchymal stem cell transplantation in stroke patients. Ann Neurol 2005; 57:874-882.

15. Lee JS, Hong JM, Moon GJ, Lee PH, Ahn YH, Bang OY; STARTING collaborators. A long-term follow-up study of intravenous autologous mesenchymal stem cell transplantation in patients with ischemic stroke. Stem Cells 2010;28:1099-1106.

16. Honmou O, Houkin K, Matsunaga T, Niitsu Y, Ishiai S, Onodera $\mathrm{R}$, et al. Intravenous administration of auto serum-expanded autologous mesenchymal stem cells in stroke. Brain 2011;134 (Pt 6):1790-1807. 
17. Bhasin A, Srivastava MV, Kumaran SS, Mohanty S, Bhatia R, Bose $S$, et al. Autologous mesenchymal stem cells in chronic stroke. Cerebrovasc Dis Extra 2011;1:93-104.

18. Hess DC, Auchus AP, Uchino K, Sila C, Clark WM, Chiu D, et al. Final results of the B01-02 phase 2 trial testing the safety and efficacy of MultiStem ${ }^{\circledR}$ in treatment of ischemic stroke. International Stroke Conference, LA, 2016.

19. Suárez-Monteagudo $C$, Hernández-Ramírez P, AlvarezGonzález L, García-Maeso I, de la Cuétara-Bernal K, CastilloDíaz $L$, et al. Autologous bone marrow stem cell neurotransplantation in stroke patients. An open study. Restor Neurol Neurosci 2009;27:151-161.

20. Battistella V, de Freitas GR, da Fonseca LM, Mercante D, Gutfilen $B$, Goldenberg RC, et al. Safety of autologous bone marrow mononuclear cell transplantation in patients with nonacute ischemic stroke. Regen Med 2011;6:45-52.

21. Savitz SI, Misra V, Kasam M, Juneja $H$, Cox CS Jr, Alderman S, et al. Intravenous autologous bone marrow mononuclear cells for ischemic stroke. Ann Neurol 2011;70:59-69.

22. Friedrich MA, Martins MP, Araújo MD, Klamt C, Vedolin $L$, Garicochea $B$, et al. Intra-arterial infusion of autologous bone marrow mononuclear cells in patients with moderate to severe middle cerebral artery acute ischemic stroke. Cell Transplant 2012;21 Suppl 1:S13-S21.

23. Li ZM, Zhang ZT, Guo CJ, Geng FY, Qiang F, Wang LX. Autologous bone marrow mononuclear cell implantation for intracerebral hemorrhage-a prospective clinical observation. Clin Neurol Neurosurg 2013;115:72-76.

24. Prasad K, Sharma A, Garg A, Mohanty S, Bhatnagar S, Johri $S$,et al. Intravenous autologous bone marrow mononuclear stem cell therapy for ischemic stroke: a multicentric, randomized trial. Stroke 2014;45:3618-3624.

25. Bang OY. Clinical trials of adult stem cell therapy in patients with ischemic stroke. J Clin Neurol 2016;12:14-20.

26. Lees JS, Sena ES, Egan KJ, Antonic A, Koblar SA, Howells DW, et al. Stem cell-based therapy for experimental stroke: a systematic review and meta-analysis. Int J Stroke 2012;7:582588.

27. Golpanian S, Schulman IH, Ebert RF, Heldman AW, DiFede DL, Yang PC, et al. Concise review: review and perspective of cell dosage and routes of administration from preclinical and clinical studies of stem cell therapy for heart disease. Stem Cells Transl Med 2016;5:186-191.

28. Caplan Al. Why are MSCs therapeutic? New data: new insight. J Pathol 2009;217:318-324.

29. Bonab MM, Alimoghaddam K, Talebian F, Ghaffari SH, Ghavamzadeh $A$, Nikbin $B$. Aging of mesenchymal stem cell in vitro. BMC Cell Biol 2006;7:14.
30. Rombouts WJ, Ploemacher RE. Primary murine MSC show highly efficient homing to the bone marrow but lose homing ability following culture. Leukemia 2003;17:160-170.

31. Hill WD, Hess DC, Martin-Studdard A, Carothers JJ, Zheng J, Hale D, et al. SDF-1 (CXCL12) is upregulated in the ischemic penumbra following stroke: association with bone marrow cell homing to injury. J Neuropathol Exp Neurol 2004;63:8496.

32. Savitz SI. Developing cellular therapies for stroke. Stroke 2015; 46:2026-2031.

33. Manganas LN, Zhang X, Li Y, Hazel RD, Smith SD, Wagshul ME, et al. Magnetic resonance spectroscopy identifies neural progenitor cells in the live human brain. Science 2007;318:980985.

34. Watson N, Ji X, Yasuhara T, Date I, Kaneko Y, Tajiri N, et al. No pain, no gain: lack of exercise obstructs neurogenesis. Cell Transplant 2015;24:591-597.

35. Jin K, Wang X, Xie L, Mao XO, Zhu W, Wang Y, et al. Evidence for stroke-induced neurogenesis in the human brain. Proc Natl Acad Sci US A 2006;103:13198-13202.

36. Darsalia V, Heldmann U, Lindvall O, Kokaia Z. Stroke-induced neurogenesis in aged brain. Stroke 2005;36:1790-1795.

37. Piccin D, Tufford A, Morshead CM. Neural stem and progenitor cells in the aged subependyma are activated by the young niche. Neurobiol Aging 2014;35:1669-1679.

38. Choumerianou DM, Martimianaki G, Stiakaki E, Kalmanti L, Kalmanti M, Dimitriou H. Comparative study of stemness characteristics of mesenchymal cells from bone marrow of children and adults. Cytotherapy 2010;12:881-887.

39. Asumda FZ, Chase PB. Age-related changes in rat bone-marrow mesenchymal stem cell plasticity. BMC Cell Biol 2011;12: 44.

40. Oh J, Lee YD, Wagers AJ. Stem cell aging: mechanisms, regulators and therapeutic opportunities. Nat Med 2014;20:870880.

41. Brohlin M, Kingham PJ, Novikova LN, Novikov LN, Wiberg M. Aging effect on neurotrophic activity of human mesenchymal stem cells. PLoS ONE 2012;7:e45052.

42. Chen J, Ye $X$, Yan T, Zhang C, Yang XP, Cui $X$, et al. Adverse effects of bone marrow stromal cell treatment of stroke in diabetic rats. Stroke 2011;42:3551-3558.

43. Popa-Wagner A, Buga AM, Doeppner TR, Hermann DM. Stem cell therapies in preclinical models of stroke associated with aging. Front Cell Neurosci 2014;8:347.

44. Kawai H, Yamashita T, Ohta Y, Deguchi K, Nagotani S, Zhang $X$, et al. Tridermal tumorigenesis of induced pluripotent stem cells transplanted in ischemic brain. J Cereb Blood Flow Metab 2010;30:1487-1493. 
45. Chen J, Li Y, Wang L, Zhang Z, Lu D, Lu M, et al. Therapeutic benefit of intravenous administration of bone marrow stromal cells after cerebral ischemia in rats. Stroke 2001;32:10051011.

46. Pendharkar AV, Chua JY, Andres RH, Wang N, Gaeta X, Wang $H_{1}$ et al. Biodistribution of neural stem cells after intravascular therapy for hypoxic-ischemia. Stroke 2010;41:2064-2070.

47. Ikegame Y, Yamashita K, Hayashi S, Mizuno H, Tawada M, You

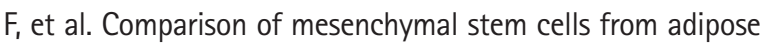
tissue and bone marrow for ischemic stroke therapy. Cytotherapy 2011;13:675-685.

48. Chan TM, Harn HJ, Lin HP, Chiu SC, Lin PC, Wang HI, et al. The use of ADSCs as a treatment for chronic stroke. Cell Transplant 2014;23:541-547.

49. Lin YC, Ko TL, Shih YH, Lin MY, Fu TW, Hsiao HS, et al. Human umbilical mesenchymal stem cells promote recovery after ischemic stroke. Stroke 2011;42:2045-2053.

50. Hsieh JY, Wang HW, Chang SJ, Liao KH, Lee IH, Lin WS, et al. Mesenchymal stem cells from human umbilical cord express preferentially secreted factors related to neuroprotection, neurogenesis, and angiogenesis. PLoS ONE 2013;8:e72604.

51. Nakanishi C, Nagaya N, Ohnishi S, Yamahara K, Takabatake S, Konno $T_{1}$ et al. Gene and protein expression analysis of mesenchymal stem cells derived from rat adipose tissue and bone marrow. Circ J 2011;75:2260-2268.

52. Szöke K, Beckstrøm KJ, Brinchmann JE. Human adipose tissue as a source of cells with angiogenic potential. Cell Transplant 2012;21:235-250.

53. Zhang L, Li Y, Zhang C, Chopp M, Gosiewska A, Hong K. Delayed administration of human umbilical tissue-derived cells improved neurological functional recovery in a rodent model of focal ischemia. Stroke 2011;42:1437-1444.

54. Li Y, Lin F. Mesenchymal stem cells are injured by complement after their contact with serum. Blood 2012;120:3436-3443.

55. Zakrzewski JL, van den Brink MR, Hubbell JA. Overcoming immunological barriers in regenerative medicine. Nat Biotechnol 2014:32:786-794.

56. Zacharek A, Shehadah A, Chen J, Cui X, Roberts C, Lu M, et al. Comparison of bone marrow stromal cells derived from stroke and normal rats for stroke treatment. Stroke 2010;41:524530.

57. Yang B, Migliati E, Parsha K, Schaar K, Xi X, Aronowski J, et al. Intra-arterial delivery is not superior to intravenous delivery of autologous bone marrow mononuclear cells in acute ischemic stroke. Stroke 2013;44:3463-3472.

58. Wei N, Yu SP, Gu X, Taylor TM, Song D, Liu XF, et al. Delayed intranasal delivery of hypoxic-preconditioned bone marrow mesenchymal stem cells enhanced cell homing and therapeu- tic benefits after ischemic stroke in mice. Cell Transplant 2013;22:977-991.

59. Wei ZZ, Gu X, Ferdinand A, Lee JH, Ji X, Ji XM, et al. Intranasal delivery of bone marrow mesenchymal stem cells improved neurovascular regeneration and rescued neuropsychiatric deficits after neonatal stroke in rats. Cell Transplant 2015;24: 391-402.

60. Borlongan CV, Hadman M, Sanberg CD, Sanberg PR. Central nervous system entry of peripherally injected umbilical cord blood cells is not required for neuroprotection in stroke. Stroke 2004;35:2385-2389.

61. Kim SJ, Moon GJ, Chang WH, Kim YH, Bang OY; STARTING-2 (STem cell Application Researches and Trials In NeuroloGy-2) collaborators. Intravenous transplantation of mesenchymal stem cells preconditioned with early phase stroke serum: current evidence and study protocol for a randomized trial. Trials 2013;14:317.

62. Efimenko A, Kochegura T, Akopyan Z, Parfyonova Y. Autologous stem cell therapy: how aging and chronic diseases affect stem and progenitor cells. BioRes Open Access 2015;4:26-38.

63. Griffiths S, Baraniak PR, Copland IB, Nerem RM, McDevitt TC. Human platelet lysate stimulates high-passage and senescent human multipotent mesenchymal stromal cell growth and rejuvenation in vitro. Cytotherapy 2013;15:1469-1483.

64. Bang OY, Moon GJ, Kim SJ, Cho YH, Sung JH, Kim SY, et al. Preconditioning and rejuvenation of mesenchymal stem cells using serum obtained at the acute phase of stroke: preclinical data of the STARTING-2 trial. 24th European Stroke Conference, Vienna, Austria, 2015.

65. Hu X, Yu SP, Fraser JL, Lu Z, Ogle ME, Wang JA, et al. Transplantation of hypoxia-preconditioned mesenchymal stem cells improves infarcted heart function via enhanced survival of implanted cells and angiogenesis. J Thorac Cardiovasc Surg 2008;135:799-808.

66. Liu H, Liu S, Li Y, Wang X, Xue W, Ge G, et al. The role of SDF$1-C X C R 4 / C X C R 7$ axis in the therapeutic effects of hypoxiapreconditioned mesenchymal stem cells for renal ischemia/ reperfusion injury. PLoS ONE 2012;7:e34608.

67. Liu H, Xue W, Ge G, Luo X, Li Y, Xiang H, et al. Hypoxic preconditioning advances $\mathrm{CXCR} 4$ and $\mathrm{CXCR} 7$ expression by activating HIF-1alpha in MSCs. Biochem Biophys Res Commun 2010;401:509-515.

68. Pasha Z, Wang Y, Sheikh R, Zhang D, Zhao T, Ashraf M. Preconditioning enhances cell survival and differentiation of stem cells during transplantation in infarcted myocardium. Cardiovasc Res 2008;77:134-142.

69. Tang YL, Zhu W, Cheng M, Chen L, Zhang J, Sun T, et al. Hypoxic preconditioning enhances the benefit of cardiac pro- 
genitor cell therapy for treatment of myocardial infarction by inducing CXCR4 expression. Circ Res 2009;104:1209-1216.

70. Choi YJ, Li WY, Moon GJ, Lee PH, Ahn YH, Lee G, et al. Enhancing trophic support of mesenchymal stem cells by ex vivo treatment with trophic factors. J Neurol Sci 2010;298:28-34.

71. Rani S, Ryan AE, Griffin MD, Ritter T. Mesenchymal stem cellderived extracellular vesicles: toward cell-free therapeutic applications. Mol Ther 2015;23:812-823.

72. Kurozumi K, Nakamura K, Tamiya T, Kawano Y, Ishii K, Kobune $M$, et al. Mesenchymal stem cells that produce neurotrophic factors reduce ischemic damage in the rat middle cerebral artery occlusion model. Mol Ther 2005;11:96-104.

73. Kurozumi K, Nakamura K, Tamiya T, Kawano Y, Kobune M, Hirai $S$, et al. BDNF gene-modified mesenchymal stem cells promote functional recovery and reduce infarct size in the rat middle cerebral artery occlusion model. Mol Ther 2004;9:189197.

74. Nomura T, Honmou O, Harada K, Houkin K, Hamada H, Kocsis JD. I.V. infusion of brain-derived neurotrophic factor genemodified human mesenchymal stem cells protects against injury in a cerebral ischemia model in adult rat. Neuroscience 2005;136:161-169.

75. Bang OY, Jin KS, Hwang MN, Kang HY, Kim BJ, Lee SJ, et al. The effect of CXCR4 overexpression on mesenchymal stem cell transplantation in ischemic stroke. Cell Med 2012;4:6576.

76. Kim SJ, Moon GJ, Cho YH, Kang HY, Hyung NK, Kim D, et al. Circulating mesenchymal stem cells microparticles in patients with cerebrovascular disease. PLoS ONE 2012;7:e37036.

77. Lai RC, Tan SS, Teh BJ, Sze SK, Arslan F, de Kleijn DP, et al. Proteolytic potential of the MSC exosome proteome: implications for an exosome-mediated delivery of therapeutic proteasome. Int J Proteomics 2012;2012:971907.

78. Sun D, Zhuang $X$, Xiang $X$, Liu Y, Zhang S, Liu C, et al. A novel nanoparticle drug delivery system: the anti-inflammatory activity of curcumin is enhanced when encapsulated in exosomes. Mol Ther 2010;18:1606-1614.

79. Zhuang $X$, Xiang $X$, Grizzle W, Sun D, Zhang S, Axtell RC, et al. Treatment of brain inflammatory diseases by delivering exosome encapsulated anti-inflammatory drugs from the nasal region to the brain. Mol Ther 2011;19:1769-1779.

80. Raisi A, Azizi S, Delirezh N, Heshmatian B, Farshid AA, Amini $K$. The mesenchymal stem cell-derived microvesicles enhance sciatic nerve regeneration in rat: a novel approach in peripheral nerve cell therapy. J Trauma Acute Care Surg 2014;76: 991-997.

81. Taylor AR, Robinson MB, Gifondorwa DJ, Tytell M, Milligan CE. Regulation of heat shock protein 70 release in astrocytes: role of signaling kinases. Dev Neurobiol 2007;67:1815-1829.

82. Xin H, Li Y, Cui Y, Yang JJ, Zhang ZG, Chopp M. Systemic administration of exosomes released from mesenchymal stromal cells promote functional recovery and neurovascular plasticity after stroke in rats. J Cereb Blood Flow Metab 2013;33:17111715.

83. Moon GJ, Sung JH, Kim DH, Cho YH, Bang OY. Mesenchymal stem cell-derived microvesicle therapy for stroke : neurogenic/angiogenic effects and biodistribution in a rat stroke model. Fourth International Meeting of the International Society for Extracellular Vesicles, Washington DC, USA, 2015.

84. Yu DC, Li QG, Ding XW, Ding YT. Circulating microRNAs: potential biomarkers for cancer. Int J Mol Sci 2011;12:20552063.

85. Caballero-Garrido E, Pena-Philippides JC, Lordkipanidze T, Bragin D, Yang Y, Erhardt EB, et al. In vivo inhibition of miR155 promotes recovery after experimental mouse stroke. J Neurosci 2015;35:12446-12464.

86. Juranek JK, Geddis MS, Song F, Zhang J, Garcia J, Rosario R, et al. RAGE deficiency improves postinjury sciatic nerve regeneration in type 1 diabetic mice. Diabetes 2013;62:931-943.

87. Xin $H$, Li Y, Buller B, Katakowski $M$, Zhang $Y$, Wang $X$, et al. Exosome-mediated transfer of miR-133b from multipotent mesenchymal stromal cells to neural cells contributes to neurite outgrowth. Stem Cells 2012;30:1556-1564.

88. Bhalala OG, Srikanth M, Kessler JA. The emerging roles of microRNAs in CNS injuries. Nat Rev Neurol 2013;9:328-339.

89. Huang $F$, Zhu $X, H u X Q$, Fang ZF, Tang $L$, Lu XL, et al. Mesenchymal stem cells modified with miR-126 release angiogenic factors and activate Notch ligand Delta-like-4, enhancing ischemic angiogenesis and cell survival. Int J Mol Med 2013; 31:484-492.

90. Yang J, Gao F, Zhang Y, Liu Y, Zhang D. Buyang Huanwu decoction (BYHWD) enhances angiogenic effect of mesenchymal stem cell by upregulating VEGF expression after focal cerebral ischemia. J Mol Neurosci 2015;56:898-906.

91. Kim EH, Kim DH, Kim HR, Kim SY, Kim HH, Bang OY. Stroke serum priming modulates characteristics of mesenchymal stromal cells by controlling the expression miRNA-20a. Cell Transplant 2016;25:1489-1499.

92. Lane SW, Williams DA, Watt FM. Modulating the stem cell niche for tissue regeneration. Nat Biotechnol 2014;32:795803.

93. Li W, Li K, Wei W, Ding S. Chemical approaches to stem cell biology and therapeutics. Cell Stem Cell 2013;13:270-283.

94. Sart S, Tsai AC, Li Y, Ma T. Three-dimensional aggregates of mesenchymal stem cells: cellular mechanisms, biological properties, and applications. Tissue Eng Part B Rev 2014;20: 
365-380.

95. Galipeau J. The mesenchymal stromal cells dilemma--does a negative phase III trial of random donor mesenchymal stromal cells in steroid-resistant graft-versus-host disease represent a death knell or a bump in the road? Cytotherapy 2013;15:2-8.

96. Bartosh TJ, Ylöstalo JH, Mohammadipoor A, Bazhanov N, Coble K, Claypool K, et al. Aggregation of human mesenchymal stromal cells (MSCs) into 3D spheroids enhances their antiinflammatory properties. Proc Natl Acad Sci U S A 2010;107: 13724-13729.

97. Frith JE, Thomson B, Genever PG. Dynamic three-dimensional culture methods enhance mesenchymal stem cell properties and increase therapeutic potential. Tissue Eng Part C Methods 2010;16:735-749.

98. Langenbach F, Berr K, Naujoks C, Hassel A, Hentschel M, Depprich $R$, et al. Generation and differentiation of microtissues from multipotent precursor cells for use in tissue engineering. Nat Protoc 2011;6:1726-1735.

99. Miyagawa $Y$, Okita $H_{1}$ Hiroyama $M$, Sakamoto $R$, Kobayashi M,

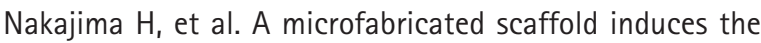
spheroid formation of human bone marrow-derived mesenchymal progenitor cells and promotes efficient adipogenic differentiation. Tissue Eng Part A 2011;17:513-521.

100. Zimmermann JA, McDevitt TC. Pre-conditioning mesenchymal stromal cell spheroids for immunomodulatory paracrine factor secretion. Cytotherapy 2014;16:331-345.

101. Bensaïd W, Triffitt JT, Blanchat C, Oudina K, Sedel L, Petite H. A biodegradable fibrin scaffold for mesenchymal stem cell transplantation. Biomaterials 2003;24:2497-2502.

102. Wang J, Yang W, Xie H, Song Y, Li Y, Wang L. Ischemic stroke and repair: current trends in research and tissue engineering treatments. Regen Med Res 2014;2:3.

103. George P, Bliss TM, Mehta S, Sun G, Steinberg GK. Abstract T MP17: Electrically preconditioned neural stem cells improve stroke recovery. Stroke 2015;46:ATMP17-ATMP17.
104. Li RK, Yau TM, Weisel RD, Mickle DA, Sakai T, Choi A, et al. Construction of a bioengineered cardiac graft. J Thorac Cardiovasc Surg 2000;119:368-375.

105. Zimmermann WH, Schneiderbanger $K$, Schubert $P$, Didié $M$, Münzel $F$, Heubach JF, et al. Tissue engineering of a differentiated cardiac muscle construct. Circ Res 2002;90:223-230.

106. Cameron CM, Hu WS, Kaufman DS. Improved development of human embryonic stem cell-derived embryoid bodies by stirred vessel cultivation. Biotechnol Bioeng 2006;94:938-948.

107. Fok EY, Zandstra PW. Shear-controlled single-step mouse embryonic stem cell expansion and embryoid body-based differentiation. Stem Cells 2005;23:1333-1342.

108. Kehoe DE, Lock LT, Parikh A, Tzanakakis ES. Propagation of embryonic stem cells in stirred suspension without serum. Biotechnol Prog 2008;24:1342-1352.

109. Niebruegge $S$, Bauwens $C L$, Peerani $R$, Thavandiran N, Masse $\mathrm{S}$, Sevaptisidis $\mathrm{E}_{\text {, et }}$ al. Generation of human embryonic stem cell-derived mesoderm and cardiac cells using size-specified aggregates in an oxygen-controlled bioreactor. Biotechnol Bioeng 2009;102:493-507.

110. Niebruegge $S$, Nehring $A$, Bär $H_{1}$ Schroeder $M$, Zweigerdt $R$, Lehmann J. Cardiomyocyte production in mass suspension culture: embryonic stem cells as a source for great amounts of functional cardiomyocytes. Tissue Eng Part A 2008;14:15911601.

111. Schroeder $M$, Niebruegge $S$, Werner A, Willbold E, Burg M, Ruediger $M$, et al. Differentiation and lineage selection of mouse embryonic stem cells in a stirred bench scale bioreactor with automated process control. Biotechnol Bioeng 2005; 92:920-933.

112. Aref A, Horvath R, McColl J, Ramsden JJ. Optical monitoring of stem cell-substratum interactions. J Biomed Opt 2009;14 (1):010501.

113. Kirouac DC, Zandstra PW. The systematic production of cells for cell therapies. Cell Stem Cell 2008;3:369-381. 